\title{
Perspektiven der Eschatologie bei Joseph Ratzinger
}

\section{1) Vorbemerkungen}

Die Eschatologie nimmt schon in einer äußerlichen Hinsicht im theologischen Werk Joseph Ratzingers eine besondere Stellung ein. Die Lehre über die christliche Hoffnung auf endgültige Vollendung von Welt und Kosmos ist der einzige dogmatische Traktat, den Ratzinger - im Jahr seiner Erhebung auf den Münchener Erzbischofsstuhl (1977) vollständig ausgearbeitet in Gestalt eines Lehrbuchs publiziert hat. Er selbst hat es später als sein „am meisten durchgearbeitetes Werk“ bezeichnet.' Die umfangreiche kirchliche Verantwortung des Erzbischofs, Kardinals, schließlich Papstes hat, wie Ratzinger in der Rückschau nicht ohne Bedauern äußert ${ }^{2}$, die Erarbeitung der übrigen ihm im Gemeinschaftsprojekt mit seinem Regensburger Kollegen und Freund Johann Baptist Auer zugedachten Teile verhindert und seine Bemühungen um einen umfassenden Neuentwurf der katholischen Dogmatik unter den Vorgaben des II. Vatikanums unvollendet gelassen.

Dass gerade die Eschatologie fertiggestellt werden konnte, ist aber kein bloßer Zufall. Im Vorwort des erwähnten Lehrbuchs weist der Verfasser selbst darauf hin, wie intensiv ihn dieses Thema im Laufe der Jahre seines akademischen Lehramts beschäftigt hat. ${ }^{3}$ Der Blick in Ratzingers theologische Bibliographie bezeugt, dass sich dieses Interesse auch publizistisch niedergeschlagen hat. Rund zwei Dutzend Einzelbeiträge, Artikel bzw. umfangreichere Teiltexte zu eschatologischen Problemen und Fragestellungen lassen sich in vier Jahrzehnten seit Ende der 50er Jahre ausmachen ${ }^{4}$, wobei Hinweise und Querbezüge aus Werken mit davon abweichenden Themen noch gar nicht berücksichtigt sind. Man wird also ohne Übertreibung von einem der echten Schwerpunkte im reichen und breit angelegten theologischen Oeuvre Joseph Ratzingers sprechen dürfen.

Im engen Rahmen dieses Überblicks kann es nicht um eine umfassende Darstellung der Eschatologie des derzeitigen Papstes gehen',

\footnotetext{
Vgl. Joseph Ratzinger, Aus meinem Leben (1998), $175 f$.

Vgl. ebd. 176.

Vgl. Eschatologie ('1977), $14 f$.

Vgl. das Literaturverzeichnis am Ende unseres Beitrags.

3 Eine ausführliche genetische Analyse der Eschatologie Ratzingers bietet die Studie von Gerhard Nachtwei, Dialogische Unsterblichkeit (1986), punktuelle Einblicke vermittelt Verweyen, Joseph Ratzinger (2007), 70-75.
} 
sondern bestenfalls um den Hinweis auf Grundzüge und Schwerpunktthemen. Dabei sollen in einem ersten Schritt einige übergreifende methodologische Charakteristika von Ratzingers Behandlung der "Letzten Dinge" benannt werden, die in gewissem Maße auch seine theologische Arbeit insgesamt zu beschreiben vermögen. Anschließend werden zwei konkrete Aspekte herausgegriffen, an deren Beispiel diese Methode ebenso wie inhaltliche Anliegen der Eschatologie Ratzingers deutlich gemacht werden können. Ausgewählt wurden zum einen Ratzingers Bestimmung der geschichtlichen Dimension eschatologischer Aussagen in der doppelten Abgrenzung gegen radikal existentialistisch-enthistorisierende Konzeptionen und gegen utopischpolitisierende Auslegungen. Zum anderen soll auf die wohl lebhafteste Debatte geschaut werden, in die Ratzinger im eschatologischen Kontext verwickelt war. Sie betrifft die Frage nach der bleibenden Bedeutung des Begriffs einer "unsterblichen Seele" für das Verstehen des nachtodlichen Schicksals des Menschen im Licht der christlichen Auferstehungsbotschaft. In einigen Schlussbemerkungen soll schließlich der Versuch unternommen werden, die theologische Mitte zu benennen, auf die alle Einzelaussagen der Ratzingerschen Eschatologie in ungebrochener Konsequenz verweisen.

\section{2) Methodologische Grundcharakteristika der Eschatologie Joseph Ratzingers}

(1) Es kann kein Zweifel daran bestehen, dass sich Ratzingers Eschatologie vorbehaltlos der theologischen Neuorientierung verpflichtet weiß, die dieser Traktat im 20. Jahrhundert, im katholischen Bereich endgültig im Umfeld des II. Vatikanischen Konzils, erfahren hat. ${ }^{6}$ Während die neuscholastischen Eschatologien noch recht stark am Schema der endzeitlichen Ereignisprophetie orientiert waren, wie es aus der auf die Wahrung des biblischen Litteralsinns bedachten Exegese seit der Väterzeit, nicht zuletzt in der Abwehr verschiedener Häresien, hervorgegangen war, hat sich die neuere Dogmatik von der Fixierung auf endzeitliche Geschehenspläne weithin gelöst. Indem das Eschatologische klarer vom bloß „Futurischen“ unterschieden wird, verzichtet es nicht nur auf die Behauptung eines exakten Wissens um zukünftige gottgewirkte Ereignisse, sondern gibt sich als Grundkategorie zu erkennen, die Jesu Botschaft vom Gottesreich und auch die darauf aufbauende christliche Heilslehre durch-

6 Vgl. etwa Balthasar, Umrisse der Eschatologie (1960); Busch, In Gottes Gemeinschaft vollendet (2001), 34-46; Müller, Die Eschatologie (2002), bes. 14-40 und 487-499. 
gängig, d. h. auch: in all ihren Zeitdimensionen prägt. Für Ratzinger steht fest: Wenn die Eschatologie über die "Letzten Dinge“ - Tod und Auferstehung, persönliches und allgemeines Gericht, Himmel, Fegfeuer und Hölle - spricht, thematisiert sie nichts anderes als das unterscheidend Christliche aus der Perspektive endgültiger Vollendungshoffnung. Eschatologie verliert damit den Charakter des theologischen Randtraktats, dessen Inhalte ganz auf das "Noch-nicht" bezogen sind, und rückt ins Zentrum christlicher Orientierung für das „Heute“.

(2) Es überrascht darum nicht, dass Ratzinger die Erläuterung vieler eschatologischer Fragen im Ausgang von Problemen angeht, die das Existenz- und Glaubensverständnis des Menschen von heute betreffen. Zur Bestätigung dieses Urteils braucht man nur darauf zu achten, wie ernst etwa seinẹ „Einführung in das Christentum“ Bultmanns Entmythologisierungskritik gegenüber vielen christologischen oder eschatologischen Sätzen des Credo 7 nimmt. Ratzingers Antwort auf diese Anfragen stellt sich durchgängig dem Anliegen einer anthropologischen Vermittlung der christlichen Glaubensbotschaft, gerade auch dort, wo sie Bultmann nicht folgen will. Walter Kasper hat diese Nähe Ratzingers zum Grundton Bultmanns in einer Rezension der "Einführung " deutlich benannt. ${ }^{8} \mathrm{Zwar}$ hat sich deren Verfasser dagegen verwahrt, dem Lager der Entmythologisierer zugerechnet zu werden', doch steht gewiss fest: Eine historisierende oder positivistische Sicht der Lehrinhalte ist Ratzingers Darstellung fremd. Das „An sich" der Glaubensinhalte wird erschlossen aus ihrem "Für uns". Damit bleibt die Darstellung fast immer streng systematisch ausgerichtet; biblische und historische Passagen sind niemals Selbstzweck, sondern stehen ganz unter dieser Zielperspektive.

Allerdings möchte sich Ratzinger nicht weniger vom entgegengesetzten Extrem theologischer Interpretation absetzen, nämlich einer Traditionsvergessenheit oder exegetischen Willkür im Umgang mit dem überlieferten Glaubensgut, wie sie Folge eines zugespitzt „existenzialen“ Theologieverständnisses sein können. „Die Anfrage der Gegenwart muss uns vor Augen stehen. Aber sie kann nicht zum Maßstab unserer Aussagen werden. Wir müssen vielmehr versuchen, von der Mitte des Christlichen her die gegenläufigen Faktoren zu integrieren, die Gewichte richtig zu setzen und die tatsächliche Zusage des Glaubens tiefer verstehen zu lernen. ${ }^{" 10}$ Das Ringen um die für einen

7 Vgl. etwa zur Himmelfahrt Christi: Einfübrung (1968), 183f; Himmelfabrt Christi (LThK); Himmelfabrt (SM), 695.

- Vgl. Kasper, Rezension (1969), hier bes. 183. Insgesamt wirft Kasper Ratzingers Aussagen einen "latenten Idealismus" vor (ebd. 185).

- Vgl. Ratzinger, Glaube, Geschichte und Philosopbie (1969), 539.

10 Eschatologie ('1977), 26; verstärkt im zweiten Anhang zur Auflage von 1980, $216 \mathrm{f}$. 
katholischen Theologen korrekte Hermeneutik im Umgang mit Schrift und Tradition ist durchweg im Werk unseres Theologen spürbar, ja es avanciert im Laufe der Jahre spürbar stärker zur formal maßgeblichen Prämisse, von der aus sich vieles Weitere entscheidet. Letztlich verbirgt sich hinter dieser Frage auch in der Eschatologie die Grundproblematik des Verhältnisses von „historischem Jesus“ und „Christus des Glaubens", welche die Theologie seit den Anfängen der historisch-kritischen Methode umtreibt und auch Joseph Ratzinger zeit seines Lebens beschäftigt hat." Sein immer wieder vorgetragenes Votum zielt nicht auf eine Missachtung kritischer Bibelwissenschaft, wohl aber auf ihre Verortung im Raum der Kirche, in der und für die der Kanon der Heiligen Schriften entstanden und festgelegt worden ist. Ungeachtet aller historischen Zweifel, wie sie aus der Schriftexegese resultieren können, sieht sich der katholische Theologe darum auf jene lebendige Auslegungsgemeinschaft verwiesen, hinter deren Zeugnis wir beim Blick auf Jesus Christus im Spiegel der vier Evangelien schlichtweg nicht zurückgehen können: „Das Wort Jesu gibt es immer nur als gehörtes, als kirchlich rezipiertes Wort. " ${ }^{12}$ So ist auch die eschatologische Botschaft des Neuen Testaments nicht zu trennen vom Prozess ihrer historischen Vermittlung in neue Verstehens- und Rezeptionskontexte hinein, deren

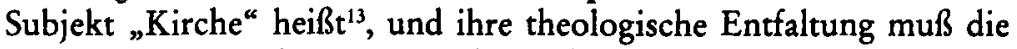
Sprachnormen und -grenzen achten, die sich in der Glaubens- und Verkündigungssprache der Kirche herausgebildet haben ${ }^{14}$, um nicht zuletzt den „Glauben der Einfachen" zu schützen. Was dies für eschatologische Einzelfragen bedeutet, werden wir im folgenden Blick auf die zwei von uns ausgewählten Beispiele konkretisieren können.

\section{3) Zwei eschatologische Zentralprobleme in der Beurteilung Ratzingers}

\section{a) Christliche Eschatologie zwischen existenzialistischer Endzeitlichkeit und chiliastischer Politisierung}

Ein Grundcharakteristikum jedes eschatologischen Entwurfs ist das ihn bestimmende Zeitverständnis. Je mehr sich die christliche Eschatologie im 20. Jahrhundert davon löste, eine bloße „Chronologie“ be-

1 Vgl. nur die Notizen über die eigenen exegetischen Lehrer im Münchener Studium: Aus meinem Leben (1998), 55-59.

12 Ratzinger, Eschatologie ( $\left.{ }^{1} 1977\right), 46$.

13 Vgl. Nachtwei, Dialogische Unsterblichkeit (1986), 238-242.

14 Vgl. Eschatologie (61980), $211 \mathrm{ff}$. 
vorstehender Ereignisse prognostizieren zu wollen, desto dringender wurde die Aufgabe anzugeben, wie die „Eschata“, von denen die Schrift spricht, in die nach Vergangenheit, Gegenwart und Zukunft geschiedenen irdischen Zeitkategorien übersetzbar sind und wieweit sie in jene übersteigende Realität Gottes hineinweisen, die wir „Ewigkeit“ nennen. Es sind vor allem zwei Ausgestaltungen des eschatologischen Gedankens in der Gegenwartstheologie, von denen Ratzinger das eigene Verständnis in verschiedenen Kontexten immer wieder abzugrenzen sucht.

(1) Die erste ist die Position des jungen Karl Barth, die in der Exegese Rudolf Bultmanns eine weitere Zuspitzung erfahren hat. Ihr Grundanliegen lautet: Damit die eschatologische Botschaft des Neuen Testaments trotz ihrer offensichtlich stark zeitbedingten, auf mythologische Sprach- und Denkformen zurückgreifenden Ausdrucksgestalt Gegenwartsrelevanz behalten kann, muss sie ihrer Zeitdimension, so weit es möglich ist, entkleidet werden. Das Wort „eschatologisch" wird dann "ein Existenzbegriff, der Christentum als ständig neuen Akt der

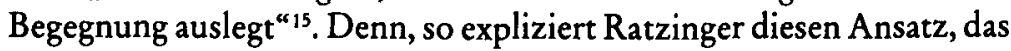
„Eigentliche des Menschen liegt nicht in den Dingen, die wir uns gegenüberstellen können, sondern im Ereignis der Begegnung. Menschliches Sein ist seinem Wesen nach Sein-können, es wird in der Entscheidung. ${ }^{16}$ Indem sich der Mensch dem ihn im Kerygma treffenden Anspruch Jesu Christi im radikalen Ernst des Glaubens stellt, erfüllt sich, worauf seine Existenz angelegt ist. Der Glaubende kann den mit historischer Gewissheit kaum zu erfassenden "Jesus des Fleisches" hinter sich lassen, um zur Begegnung mit dem als auferstanden verkündeten pneumatischen Christus zu gelangen. Sie allein zählt.

Bei aller Faszination, die diese „Eschatologie als Antithese zu Heilsgeschichte "17 ausstrahlen mag, hält Ratzinger sie doch für „zu teuer erkauft. "18 Ihre Problematik liegt in der Prämisse, "dass das Christentum außerhalb der Wirklichkeit, auf der Nadelspitze des Augenblicks angesiedelt wird. Ein Glaube, der mit der Geschichte (mit der erfahrbaren Wirklichkeit überhaupt) nicht in Konflikt kommen kann, hat der Geschichte auch nichts mehr zu sagen ${ }^{\prime \prime}{ }^{19}$ Ratzinger wirft der Existen-

is Eschatologie ('1977), 51.

16 Ebd. 52.

17 So Ratzingers Charakterisierung des Bultmannschen Standpunkts in seiner Tübinger Antrittsvorlesung: Heilsgeschichte und Eschatologie (1967), 72-75. Zum ersten Mal kritisiert Ratzinger in diesem Beitrag übrigens die Eschatologie Greshakes, und zwar dadurch, dass er sie als einen "völlig unkritischen, aber recht

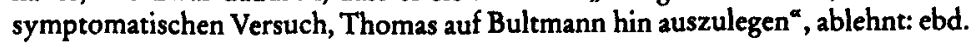
76, Anm. 18.

Ebd. 
zialtheologie also vor, theologische Bedeutung derart auf eine von der Gesamtheit alltäglicher Wirklichkeitserfahrung isolierte Ebene zu verlagern, dass mit der Reduktion des Wirklichkeitsbegriffs auch die angezielte theologische Relevanz unwirklich wird. Dass die umfassende Entgeschichtlichung der Eschatologie nicht lange befriedigt, hat sich nach Ratzinger darin gezeigt, dass sie faktisch der radikalen Gegenbewegung, der konsequent verzeitlichten Eschatologie des Marxismus, den Einzug in die Theologie erleichtert hat: „In das entweltlichte Christentum kehrt die Welt mit Macht zurück. " 20

(2) Damit stehen wir vor dem zweiten großen Auslegungsstrang der eschatologischen Botschaft, mit dem sich Ratzinger immer wieder beschäftigt und den er durchweg noch entschiedener als den erstgenannten zurückgewiesen hat. Man könnte ihn die politisch-utopische Variante der Eschatologie nennen, und er ist in der Geschichte der christlichen Theologie sogar fester verankert als der zuvor genannte existenziale Zugang.

Ratzingers Beschäftigung mit einer verzeitlichten Eschatologie reicht bis in die Zeit seiner Münchener Habilitation zurück. Die Geschichtsphilosophie Bonaventuras, des führenden Franziskanertheologen in der zweiten Hälfte des 13. Jahrhunderts, erweist sich in seiner Darstellung als eschatologische Korrektur des auf ein innerweltliches Vollendungszeitalter hinauslaufenden Utopie, die der Abt Joachim von Fiore propagiert hatte und die sich bald als Sprengstoff für den stets für visionäre Radikalismen empfänglichen jungen Franziskanerorden erwies. ${ }^{21}$ Dieser Chiliasmus, wie er in der mittelalterlichen Lehre Joachims paradigmatisch zum Ausdruck kam, hat uralte Wurzeln bis in die frühjüdische Zeit hinein und ist durch die dort aufbrechende apokalyptische Bewegung nicht gebannt, sondern sogar befördert worden. In säkularisierter Form hat er nach Ratzinger noch die politische Theorie der Neuzeit bis zu Hegel, Marx und den Befreiungstheologen des 20. Jahrhunderts entscheidend geprägt. ${ }^{22}$ In Jürgen Moltmanns "Theologie der Hoffnung" bleibt sein Nachhall ebenso vernehmbar wie in Johann Baptist Metz " "politischer Theologie ${ }^{\alpha 23}$ und anderen emanzipatorischen Entwürfen der Gegenwart, in denen „Christentum als Weltveränderung vom Maßstab der Hoffnung “ her verstanden wird. In der langen Spur des utopisch-chiliastischen Denkens begegnet man immer wieder dem gleichen Schema: Übergeschichtliches (letzte Vollendung) wird in der Geschichte selbst erwartet, und diese Erwartung soll durch aktives

\footnotetext{
20 Ebd.

21 Vgl. Geschichtsphilosophie (1959), bes. 106-120.

22 Vgl. etwa Zukunft des Heils (1975), 47f.; Eschatologie und Utopie (1977), 100ff.;

Politik und Erlösung (1986).

23 Vgl. Eschatologie ('1977), 58.
} 
Handeln befördert werden. Endzeithoffnung wird umgeschmolzen zur "theopolitischen Aussage" und Aktion. Damit aber ist die Gefahr unvermeidbar, dass am Ende die Geschichte selbst „die eigentliche Gottheit der Utopie [ist], die nicht nur die Attribute und die Macht der Gottheit an sich gezogen hat, sondern auch ihren unbedingten Verehrungs- und Gehorsamsanspruch wie die Unbedingtheit ihrer VerheiBungen ${ }^{24}$.

Dieser radikalen Verzeitlichung und Politisierung des Eschatologischen tritt Ratzinger vom Begriff des Reiches Gottes her entgegen, wie er in der Verkündigung Jesu zu finden ist. „Das Reich Gottes“, so betont unser Theologe, „ist kein politischer Begriff und daher auch kein politischer Maßstab, von dem her unmittelbar politische Praxis aufgebaut werden kann und Kritik an politischen Verwirklichungen zu üben ist. Die Herbeiführung des Reiches Gottes ist kein politischer Prozess, und wo sie dennoch als solcher gefasst wird, wird beides verfälscht: die Politik und die Theologie. Dann entstehen falsche Messianismen, die ihrem Wesen nach und vom inneren Anspruch des Messianischen her, der hier auf die falsche Ebene tritt, zu Totalitarismen werden. ${ }^{25}$ Doch nicht nur aus theologischen, auch aus prinzipiellen anthropologischen Gründen können nach Ratzinger Hoffnungen auf gezielte Herbeiführung bzw. Beförderung des Reiches Gottes in der Geschichtszeit niemals ihr Ziel erreichen. Die Vergeschichtlichung der Eschatologie scheitert am Wesen menschlicher Freiheit, die stets offen für Sünde und Versagen bleibt und darum jedes Konzept von Heil als endgültigem Ergebnis planbarer Mechanismen, jede „Physik des Menschlichen“, zu der die politisierten Erlösungslehren notwendig mutieren ${ }^{26}$, ad absurdum führen muss. Utopisches Denken, so lautet das harsche Gesamturteil ${ }^{27}$, erweist sich am Ende als „irrationale Verheißung ${ }^{48}$, ja als „ein primitiver Mythos “29 mit häufig schlimmen Folgen für die Realität.

(3) Die eigene Lösung, die Ratzinger den beiden abgelehnten Alternativen der radikalen Entgeschichtlichung wie der radikalen Verge-

24 Politik und Erlösung (1986), 18.

25 Eschatologie ( $\left.{ }^{1} 1977\right), 59$.

26 Politik und Erlösung (1986), 21.

27 Wer in das Jesus-Buch Benedikts XVI. blickt, erkennt rasch, dass die Polemik gegen „utopistisches Gerede ohne realen Inhalt" (Jesus von Nazaretb [2007], 84) im Verständnis des "Reiches Gottes" und die damit drohende politische Instrumentalisierung des Religiösen unvermindert präsent geblieben ist. Verweyen, Joseph Ratzinger (2007), 71, hat seinem Lehrer jüngst eine zu undifferenzierte Darstellung der an Autoren wie Metz oder Moltmann orientierten „Theologie der Hoffnung vorgeworfen, geht aber seinerseits auf Ratzingers Gründe für die Ablehnung nur sehr oberflächlich ein. 
schichtlichung der Eschatologie entgegenstellt, entfaltet ein grundsätzlich heilsgeschichtlich orientiertes und christologisch zentriertes Verständnis endzeitlicher Vollendung, auf dessen Konzipierung die Arbeiten des Basler Neutestamentlers Oscar Cullmann ${ }^{30}$ und ihre Rezeption bei Jean Daniélou S. J. ${ }^{31}$ ebenso prägenden Einfluß ausgeübt haben wie die Forschungen des Oxforder Exegeten Charles H. Dodd. "Mitte" und „Ende" der Zeit, so hatte Cullmann aufgezeigt, stehen in einer bleibenden Diastase, in der Spannung zwischen "Schon" und "Noch-Nicht". Mit Jesus Christus hat das Ende der Welt definitiv begonnen, aber es wäre naiv, seine Erfüllung innergeschichtlich zu erwarten (sei es im Sinne einer politischen Revolution oder im Sinne neuzeitlichen Fortschrittsglaubens). Christus allein ist der Punkt der Weltgeschichte, der die bereits geschehene Erlösung und die bislang ausstehende Vollendung zusammenhält. Er ist nach einem von Ratzinger (bis in das jüngste Jesus-Buch) gerne zitierten Origenes-Wort die autobasileia, das Gottesreich in Person..$^{32}$ "Die Antwort auf die Frage des Reiches ist der Sohn. In ihm ist auch die unschließbare Diastase von Schon und Noch nicht geschlossen: In ihm sind Tod und Leben, Vernichtung und Sein zusammengehalten. Das Kreuz ist die Klammer, die die Diastase schließt. " 33 Der Weg in die Erlösung hinein, so spitzt Ratzinger darum den heilsgeschichtlichen Grundansatz in spürbarer Nähe zum Denken Hans Urs von Balthasars christologisch zu, geschieht allein durch Teilnahme am Geschick Jesu von Nazareth, das unweigerlich zum Kreuz führt. „Der Leib des Sohnes ist die Brücke unserer Seelen. ${ }^{34}$ Christliche Vollendung ist Transformation auf dem Weg durch Sterben und Tod, durch Selbsterniedrigung statt Selbsterhöhung, durch Kreuzesgehorsam statt prometheischer Aktivität. „Der Mensch kann ,Gott' werden, aber nicht dadurch, dass er sich dazu macht, sondern allein dadurch, dass er ,Sohn' wird. Dort, in der Sohnesgebärde Jesu, nirgend anders, geht das ,Reich Gottes" auf. " ${ }^{\text {"3s }}$ Das Eschaton wird berührbar in der Begegnung mit Jesus Christus, es eröffnet sich im Mitgehen seines Weges, der nicht in dieser Welt endet. Vollendung des Ganzen aber wird wie die schon geschehene Erlösung, nicht menschliche Aktion, sondern ganz und gar Tat Gottes in Christus

30 Vgl. bes. Oscar Cullmann, Christus und die Zeit (Zürich ${ }^{31962) .}$

31 Vgl. Ratzingers Ausführungen unter dem Titel „Heilsgeschichte als Antithese $z u$ Metaphysik" in: Heilsgeschichte und Eschatologie (1967), 69-72. Die eigene Antwort (82-89) macht Ratzingers Nähe zum heilsgeschichtlichen Denken deutlich. An die explizit antimetaphysische Stoßrichtung mancher Vertreter dieser Linie knüpft er aber nicht an.

Vgl. Eschatologie ('1977), 41; Jesus von Nazareth (2007), 79, 181, 226 u.ö.

Ebd. Eschatologie (11977), 64.

Damit Gott alles in allem sei (1993), 136.

Eschatologie ( $\left.{ }^{1} 1977\right), 63$. 
sein - dafür steht der Glaube an die Parusie des Herrn, wie ihn das Credo einschließt.

Verliert die eschatologische Botschaft damit jede politische Dimension? Ratzinger verneint diese Frage. Auch wenn das Gottesreich als solches niemals "politische Norm" zu sein vermag, weil der Mensch es in Christus empfangen muss und nicht selbst in der Geschichtszeit herbeizwingen kann, so behält es doch seine Relevanz für die Politik - freilich nicht als zu erstrebender geschichtlicher Zustand, sondern "auf dem Weg über die politische Ethik“, als moralische Norm in einer nicht deterministisch auf einen utopischen Endzustand hin planbaren, sondern bleibend offenen, auch zukünftig durch Freiheit bestimmten Geschichte. ${ }^{36}$ Der in Christus seine Herrschaft ansagende Gott offenbart sich als die fleischgewordene Wahrheit und Gerechtigkeit und damit als unbedingter Maßstab und Wert menschlichen Handelns in individueller wie gesellschaftlicher Perspektive. ${ }^{37}$ Hier zeigt sich die untrennbare Verbindung christlicher Geschichtstheologie mit einem ontologisch orientierten platonischen Ordnungsmodell und damit ganz generell die innere Konvergenz von christlichem und griechischplatonischem Logos, die sich im Laufe der Jahre als eine Grundkonstante erwiesen hat, die das Denken Joseph Ratzingers in vielerlei Hinsicht prägt und durchzieht.

\section{b) Unsterblichkeit der Seele und Auferstebung der Toten?}

(1) In allen neueren Debatten um die Eschatologie ist die spätestens seit Harnack allgegenwärtige Antithese von biblischem und griechischem Denken präsent. Sie konkretisiert sich in der Ablehnung des Seelenbegriffs, durch die sowohl die Theologie des Todes wie auch das Verständnis von Auferstehung bei vielen Autoren einen radikalen Wandel erfahren haben. Die Gegenüberstellung lautet zumeist: In der ontologisch konzipierten griechischen Anthropologie bezeichnet der Begriff der "Seele" den durch seine Geistigkeit unsterblichen Wesensbestandteil des Menschen, dem der Leib als wegen seiner Materialität sterbliches Moment gegenübersteht. In der biblischen Sicht dagegen ist "Mensch“ stets als ganzer im Blick; wenn ihm Unsterblichkeit zugeschrieben wird, dann nicht aufgrund irgendeines ontischen Eigen-Seins, sondern durch seine Relation zum lebendigen Gott. Als zu stark vom Platonismus und nicht konsequent genug von biblischer Anthropologie geprägt, hat die eschatologische Tradition der christlichen Theologie auf

\footnotetext{
36 Ebd. 59.

37 Vgl. Eschatologie und Utopie (1977), 106; Politik und Erlösung (1986), 21-24.
} 
diesem Hintergrund auch unter katholischen Autoren im 20. Jahrhundert zuweilen heftige Kritik erfahren.

Ratzinger erwähnt im Vorwort seiner „Eschatologie“, dass er selbst ursprünglich zu den klaren Verfechtern der Entplatonisierungsforderung zählte. Er fügt jedoch an: „Je länger ich aber mit den Fragen umging, je mehr ich mich in die Quellen vertiefte, desto mehr zerfielen mir die aufgebauten Antithesen unter der Hand und desto mehr enthüllte sich die innere Logik der kirchlichen Überlieferung. ${ }^{38}$ Während manche vor 1970 entstandenen Texte das griechische und das biblische Modell recht klar als Alternativen gegenüberstellen und "Seele“ als Zentralbegriff einer ontologisch konzipierten Unsterblichkeitsauffassung bestenfalls als sekundäre, aspektzentrierte, nicht bis ins letzte überzeugende Interpretationskategorie der dialogisch grundgelegten biblischen Anthropologie anerkennen ${ }^{39}$, tendiert Ratzinger im 1977 erschienenen Lehrbuch dazu, die „fast panische Furcht vor dem Vorwurf des Dualismus ${ }^{40}$ in Aussagen der neueren Theologie, die sich mittlerweile auch liturgisch (Tilgung des Seelenbegriffs im Messbuch Pauls VI.) niedergeschlagen hat, skeptisch zu konnotieren. Die Alternative "Unsterblichkeit der Seele" oder „Auferweckung der Toten" hat sich dem Regensburger Theologen im Laufe der Jahre endgültig als falsche Entgegensetzung erwiesen. Ihm hat sich zunehmend deutlicher gezeigt, dass viele Interpreten, die scharf die Dualismus-Aporien „griechischer" Anthropologie benennen und sich damit begnügen, ihr den biblischen Auferweckungsglauben als "ganzheitliche" Alternative entgegenzustellen, dazu tendieren, die kaum geringeren Probleme auszublenden, die auch mit ihm für unseren Verstand verbunden sind. Schon in einem Text von 1972 stellt Ratzinger grundsätzlich zum theologischen Verstehen unseres nachtodlichen Schicksals fest: „Dass hier

3s Eschatologie ('1977), 14.

39 Vgl. etwa die Artikel Auferstehung des Fleisches (LThK), 1049ff. und Auferweckung (SM), wo es apodiktisch heißt: „Die Hoffnung auf die Auferweckung der Toten ist die biblische Form des Unsterblichkeitsglaubens [...]" (397). Mit dem Auferweckungsgedanken ist der griechische Seelenbegriff eine eher ,additive Synthese" eingegangen, die der mittelalterlichen Theologie dauerhafte Probleme eingebracht hat. Denn: „In Wahrheit handelt es sich ursprünglich nicht um zwei komplementäre Vorstellungen, sondern um je eine Totalantwort auf das Problem der menschlichen Zukunft “ (398). Freilich wird ,eine gewisse Begegnung [sc. der Auferweckungshoffnung] mit der griechischen Unsterblichkeitsidee und ihre Transformation ins Christliche ${ }^{\alpha}$ für möglich erachtet: Sie kann „immerhin zum Ausdruck werden für die wesentliche Unvergänglichkeit, die dem Menschen ganz allgemein aufgrund der besonderen Art seines Gewolltseins und Gerufenseins von Gott zukommt, das in den christologischen Aussagen seine eigentliche Deutung und Erfüllung erfährt " (401). Ähnlich in ausführilicherer Form: Einführung (1968), 290-297.

40 Eschatologie ( $\left.{ }^{6} 1980\right), 217 \mathrm{f}$. 
ohne vernünftiges Mitdenken mit der inneren Richtung der biblischen Aussagen, das heißt, ohne deren philosophische Vermittlung (ohne ,Hermeneutik') kein Weg weiterführt, ist offenkundig. Und dann kann die Frage nicht mehr verboten sein, ob etwas wie der Begriff, Seele' als hermeneutisches Bindeglied nicht doch notwendig ist, ja, vom Befund her selber sich aufdrängt, auch wenn dieser seine Reflexion nur ansatzweise in diese Richtung vortreibt. ${ }^{* 41} 1977$ dann spricht unser Theologe - freilich in einem etwas anderen Kontext - von der kirchlichen Eschatologie sogar als einem „Produkt der Verschmelzung von christlichem Glauben und griechischer Suche nach dem Logos, der zusammenhaltenden Vernunft der Dinge. ${ }^{42}$ Dieses Urteil wird konkret in Ratzingers Votum für „eine Rehabilitierung der tabuisierten Begriffe, Unsterblichkeit' und ,Seele in der Theologie. ${ }^{{ }^{4} 3}$

Zum Bẻleg seiner neuakzentuierten Bewertung entfaltet Ratzinger vor allem zwei Argumentationslinien. Zum einen will er nachweisen, dass das Alte Testament gar nicht durch fremden, griechischen Einfluss, sondern in seiner eigenen, genuin theologischen Entwicklung zu der Idee einer Unsterblichkeit des Menschen nach seinem physischen Tod gelangt ist, die nicht mit dem Auferstehungsgedanken im Widerspruch steht, mit ihm aber auch nicht zusammenfällt und die deswegen von sich aus nach dem Seelenbegriff verlangt. Zweitens bemüht sich Ratzinger aufzuzeigen, dass das Problem des "Zwischenzustands", der den Tod des Menschen von der allgemeinen Auferstehung am Ende der Zeiten trennt, vor allem aus zeit- und geschichtsphilosophischen Gründen nicht eliminiert und nicht ohne Rekurs auf den Seelenbegriff bewältigt werden kann. Spätestens an dieser Stelle wird die Auseinandersetzung mit theologischen Entwürfen der Gegenwart unvermeidlich, die eine Alternative zum klassischen Zwischenzustandsdenken vorzulegen versuchen. Bekannt geworden ist vor allem Ratzingers strikte Ablehnung des auch im katholischen Raum verbreiteten Modells einer "Auferstehung im Tod “. ${ }^{44}$

(2) Schauen wir zunächst auf den ersten Argumentationsstrang. Biblisches Denken, so betont Ratzinger immer wieder, steht in einer lebendigen Entwicklungsbewegung, die sich bei näherem Betrachten als getrieben durch das sich schrittweise vertiefende Gottesverständnis Israels erweist. Dies gilt auch für das Verständnis der Themen Tod und Unsterblichkeit. Die ältere Sicht des Todes, wie sie in den Schriften des Alten

4 Jenseits des Todes (1972), 234.

42 Eschatologie und Utopie (1977), 98.

4) Jenseits des Todes (1972), 241.

4 Vgl. zum folgenden auch die - eher aus der theologischen Perspektive Greshakes - verfassten Kapitel bei Busch, In Gottes Gemeinschaft vollendet (2001), 119-160, 221-233. 
Testament greifbar wird, kann nach Ratzinger eigentlich nur auf dem Hintergrund eines noch nicht vollständig entfalteten Gottesverständnisses einleuchten. Der Tod wird darin zwar nicht als Vernichtung, wohl aber als Abstieg des Menschen in die Scheol als Ort der schattenhaften Beziehungslosigkeit angesehen. Kann dies noch gedacht werden, wo sich der Glaube an einen lebendigen Gott durchgesetzt hat, der das menschliche Dasein als absolute Beziehungsgröße ganz und gar ermöglicht und prägt? Dann scheint doch vielmehr gelten zu müssen, dass „letzten Endes nur entweder der Jahwe-Glaube aufgehoben werden [konnte], oder die Schrankenlosigkeit von Jahwes Macht und damit die grundsätzliche Endgültigkeit der von ihm gestifteten Gemeinschaft [...] hervortreten" muss$\mathrm{te}^{45}$. Darum setzte sich die Einsicht durch: Jahwe selbst ist das Leben der Toten. Diese Erkenntnis wurde durch die Krisen von Leid- und Sinnlosigkeitserfahrungen, wie sie etwa in den Büchern Ijob oder Kohelet biblisch-literarischen Niederschlag gefunden haben, vor allem aber durch die Prüfung des Exils geläutert und vertieft. Am Ende ist der Todesbereich als positiver Gehalt deutbar geworden: Leiden hat sich als Weg des Gerechten zu Gott enthüllt. Indem der alte Tun-Ergehen-Zusammenhang zerbrach, trat die Gottesgemeinschaft als die eigentliche, auch das Todesverständnis umgreifende Wirklichkeit hervor. Diese Grundeinsicht, dass Hoffnung auf Leben nach dem Tod aus der unzerstörbaren Beziehung zu Gott erwächst, gewinnt in Jesus Christus Endgültigkeit. Denn in ihm „ist Gott selbst in den Bereich des Todes eingetreten und hat den Raum der Kommunikationslosigkeit zum Raum seiner Anwesenheit gemacht. Das ist nicht Glorifizierung des Todes; indem Gott ihn durch Christus heimgesucht hat, hat er ihn als Tod aufgehoben und überwunden " ${ }^{46}$. Die Hoffnung auf Unsterblichkeit definiert sich konkret nun vom Blick auf das Kreuz Christi als das Symbol einer Liebe, die sich durchhält im radikalen Sich-Verschenken. Sie wird das Maß für jedes christliche Verständnis des Todes. „Der Christ weiß: Er kann die Selbstenteignung, die ihm fortwährend widerfährt, verschmelzen mit der Grundgesinnung eines auf Liebe geschaffenen Wesens, das sich gerade im Vertrauen auf das nicht zu erzwingende Geschenk der Liebe unbedingt geborgen weiß. Der Tod, der Feind des Menschen, der ihn berauben, ihm das Leben stehlen will, wird besiegt, wo der Mensch dem Raubzug des Todes mit der Gesinnung der vertrauenden Liebe entgegentritt und so den Raub umwandelt in ein Mehr an Leben. ${ }^{47}$ Wenn die Christen aus der Begegnung mit dem Auferstandenen ${ }^{48}$ schon seinem Tod rechtfertigende Kraft zuschreiben, dann

45 Ratzinger, Eschatologie ('1977), 76.

46 Ebd. 84.

47 Ebd. 87.

48 Vgl. Die Auferstehung Christi und die christliche Jenseitshoffnung (1972), 34: „Diese konkrete Erfahrung gab ihnen eine unmittelbare Gewissheit, dass es ein 
geben sie damit ihrem Glauben Ausdruck, dass Erlösung dort zu finden ist, wo Menschen sich gläubig hineinnehmen lassen in Jesu Übereignung an die Wahrheit Gottes, die größer ist als das eigene Ich. In Christus zeigt sich mit abschließender Klarheit, warum und wie menschliche Existenz auch im Angesicht des Todes als unzerstörbar geglaubt werden darf. Wiederum ist es nicht griechische Geistphilosophie, die sich hier zur Durchsetzung bringt, sondern biblische Anthropologie, die ihre Gestalt gefunden hat aus der Begegnung mit dem sich immer mehr als er selbst, d. h. als Liebe offenbarenden Gott. Weil Gott in Jesus Christus konkrete menschliche Gestalt angenommen hat, wird die Gottesbeziehung für den Glaubenden real als Christusbeziehung, ist das bleibende Sein der Toten ihr "Sein in Christus“49.

So lautet das Fazit aus der Betrachtung des langen biblischen Erkenntnisweges in der Todesfrage: „Das Unsterblichkeitsverlangen steigt nicht aus der isolierten, in sich verschlossenen Existenz auf, die unbefriedigend ist, sondern aus der Erfahrung der Liebe, der Gemeinschaft, des $\mathrm{Du}^{\text {“so }}$, letztlich des gott-menschlichen Du Jesu Christi. Auferstehungsglaube und Gottesglaube sind in diesem Sinne geradezu identisch ${ }^{51}$. Ratzinger widerruft also keineswegs die These, dass das biblische Unsterblichkeitsverständnis dialogisch-relational konzipiert ist. Er sieht aber die vollendet reflektierte Gottesbeziehung, wie sie die Schrift bezeugt, in ein Verständnis von Nicht-Vergehen im Tode münden, das als solches noch nicht identisch ist mit der Hoffnung auf endgültige Vollendung in der universalen Auferstehung ${ }^{32}$, wiewohl es erst in ihr sein Ziel findet.

(3) Mit dem so geführten Nachweis einer sich genuin theologischchristologisch entfaltenden Entwicklungstendenz der biblischen Sicht von "Unsterblichkeit" ist der entscheidende Schritt zur Verteidigung des traditionellen Begriffs einer "unsterblichen Seele“ bereits getan. „Der Mensch kann deswegen ewig leben, weil er der Beziehung zu dem fähig ist, was Ewigkeit gibt. Das, woran diese Beziehung im Menschen einen Anhalt findet, nennen wir ,Seele'. Seele ist nichts anderes als die Beziehungsfähigkeit des Menschen zur Wahrheit und zur ewigen Liebe $e^{\alpha s 3}$, die Mensch geworden ist in Jesus Christus. Der Seelenbegriff

Leben nach dem Tode gibt, eine Erweckung aus der Welt des Todes heraus, in der sie die Verheißung ihrer eigenen Auferweckung erkannten."

49 Auf die christologische Konkretisierung der eschatologischen Hoffnung im Neuen Testament weist Ratzinger schon in seinen älteren Beiträgen immer wieder hin; vgl. etwa Awferweckung (SM) 400f.

so Eschatologie ('1977), 85.

31 Vgl. Eschatologie ('1980), 223.

52 So explizit ebd. 214.

53 Vgl. Eschatologie ('1980), 223. 
benennt die in Christus konkretisierte Gottbezogenheit des Menschen als anthropologisches Existenzial, als ontologisches Konstitutivum des Menschseins. Es ist dieser spezifisch biblisch-christlich geprägte $\mathrm{Be}-$ griff von „Unsterblichkeit" und „Seele“, der sich im Laufe der Theologiegeschichte - gewiss in Anknüpfung an griechische Vorgaben, aber zugleich in modifizierender Abgrenzung von ihnen - herausgebildet hat. In der thomanischen Lehre von der "anima (unica) forma corporis“ ist er im Mittelalter zu einer gewissen Vollendung gelangt und kann heute mit personal-dialogischen Kategorien noch besser von einseitigen substanzontologischen Implikationen befreit werden..$^{54}$

(a) Freilich weiß Ratzinger, dass mit solchen Grundaussagen nicht automatisch alle Fragen in der Suche nach einer angemessenen anthropologischen Denkform für die Eschatologie gelöst sind. Ein bleibendes Problem betrifft den Zustand des Menschen zwischen individuellem Tod und allgemeiner Auferstehung, den die traditionelle Eschatologie mit Hilfe des Begriffs der unsterblichen Seele zu beschreiben sucht. Hier muss er sich auch in der von Ratzinger präferierten relationaldialogischen Explikationsgestalt bewähren. Konkret gefragt: Ist es tatsächlich sinnvoll und akzeptabel, im Menschen eine Seele als geistiges Formprinzip anzusetzen, das sich im Tod vom Leib trennt, in dieser Trennung als nicht-personale Entität subsistiert (d. h. ohne ontologischen Träger oder Verbindung mit einer von ihr verschiedenen Größe für sich fortbesteht) und das in der unmittelbaren Anschauung Gottes seine (zumindest intensiv) nicht weiter steigerbare Glückseligkeit findet, ohne zugleich das Bedürfnis nach Wiedervereinigung mit dem eigenen Leib zu verlieren, wie sie dann durch Gott in der Auferstehung ermöglicht wird? Exakt dies war die Lehre der scholastisch geprägten katholischen Dogmatik über Tod, vom Leib getrennte Seele und Auferstehung.

Das 20. Jahrhundert hat auch innerhalb der katholischen Theologie den Ruf nach Alternativentwürfen zu dieser Konzeption laut werden lassen. Neben der schon erwähnten Kritik aus der Perspektive der bi-

34 Vgl. Jenseits des Todes (1972) 240f.; Auferstehung und ewiges Leben (1973), 308:

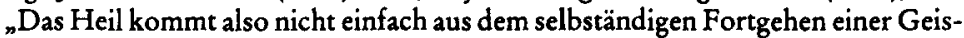
tessubstanz, die von der Materie gelöst nun aus Eigenem weiterbesteht und zu den Materieteilen, die ihr einstmals anhafteten, nur noch einen sehr beiläufigen Bezug haben kann, sondern es ist Heil des Menschen, dieser bestimmten Kreatur Gottes, die trotz ihres unbestrittenen ontologischen Schichtenbaues doch eine echte Einheit, ein einziges Werk des göttlichen Meisters ist. Diese völlig anders geartete Gegenüberstellung Schöpfer-Geschöpf (statt Seele-Leib) steht am Wurzelpunkt der biblischen Heilslehre und bestimmt den der griechischen Philosophie so fremd erscheinenden ganzheitlichen Ansatz, der sich in der Auferstehungsidee eine zentrale Ausdrucksform geschaffen hat ${ }^{\alpha}$; Eschatologie (1977), 119-135. 
blischen Auferstehungsbotschaft sind in der Debatte innere Widersprüche im "anima separata"-Denken ebenso zur Sprache gebracht worden wie speziellere Argumente, die sich etwa in einer anthropologischen Auswertung des Assumpta-Dogmas von 1950 nahezulegen scheinen.

Da Ganztodtheorien oder Luthers Lehre vom Seelenschlaf mehr Probleme aufwerfen, als sie beseitigen, bleibt als einzig ernstzunehmendes Alternativkonzept zur klassischen $Z$ wischenzustandslehre das Modell einer „Auferstehung im Tode“. Wenn Ratzinger sich mit ihm auseinandersetzt, dann konkret mit Blick auf die Arbeiten Gisbert Greshakes, der seit seiner 1969 erschienenen Münsteraner Dissertation und der fünf Jahre später gemeinsam mit dem Tübinger Neutestamentler Gerhard Lohfink vorgelegten "Quaestio disputata“ zur Auferstehungsfrage als ihr einflussreichster Vertreter im katholischen Raum gelten darf.

Die Kernthese Greshakes lautet, knapp zusammengefasst: Im Sterben des Menschen trennt sich nicht eine unzerstörbare Seele von einem zerstörbaren Leib, sondern der in die ewige Vollendung bei Gott hinübergehende Mensch ist als ein ganzer zu betrachten - wobei Leiblichkeit freilich nun nicht mehr als physische Körperlichkeit zu verstehen ist, sondern als das in der verendgültigten personalen Wirklichkeit aufgehobene Moment menschlicher Relationalität und Kommunikationsfähigkeit. ${ }^{55}$ Wenn der irdische Leib im Grab verbleibt, ist dies kein Argument gegen den Glauben, dass der Verstorbene bereits mit „Leib und Seele" bei Gott weilt. Damit will Greshake sowohl das problematische Konzept der leibfreien Seele wie die mythologisch anmutende Vorstellung einer physizistisch konzipierten Auferstehung des Leibes vermeiden.

(b) In seinem 1977 publizierten Eschatologie-Lehrbuch erhebt Ratzinger (wie auch verschiedene andere Theologen) gegen Greshakes Auslegung der kirchlichen Lehre erhebliche Vorwürfe. Greshake selbst hat von einem "Paukenschlag" gegen die Hypothese von der „Auferstehung im Tode" gesprochen. ${ }^{36}$ Vor allem zwei der Kritikpunkte sind der näheren Darlegung wert. ${ }^{57}$

35 Über den Hintergrund dieser These Greshakes bei Rahner, Boros und Metz informiert Sonnemans, Seele (1984), 413-424. Was Greshake anzielt, so faßt es Sonnemans knapp zusammen, ist "Leib in Seele ${ }^{\prime}$, "Welt in Geist" (419). Ausführlicher unterrichten über Greshakes Auferstehungslehre: Kirk, Tod und Auferstebung (1986), 370-380; Nachtwei, Dialogische Unsterblichkeit (1986), 120-127; Busch, In Gottes Gemeinschaft vollendet (2001). Vgl. Greshake, Rezension (1978), 481.

57 Vgl. zum folgenden Ratzinger, Eschatologie ( $\left.{ }^{1} 1977\right)$, 96ff. und ( $\left.{ }^{6} 1980\right), 218 f . ; Z w i-$ schen Tod und Auferstebung (1980) 216ff. Ausführliche Analyse bei Nachtwei, Dialogische Unsterblicbleit (1986), 127-140. 
(aa) Erstens wirft Ratzinger seinem Kollegen ein letztlich inakzeptables Verständnis von "Leiblichkeit" vor. Indem dieser sie allein als „ekstatisches Moment des menschlichen Freiheitsaktes“ fasst, trennt er sie völlig von der Beziehung zur „Materie“, wie wir sie in unserer derzeitigen Lebenswelt kennen. Von der thomanischen „anima-formacorporis-Lebre" her, auf die sich Greshake immer wieder beruft, ist diese Interpretation mit ihrem auf Rahner zurückweisenden ${ }^{58}$ Implikat, dass die Seele die Materie „als Materie im ewig Unvollendbaren dann definitiv hinter sich lässt ${ }^{459}$, nach Ratzinger nicht gedeckt. Vielmehr läuft die Thomas-Lektüre Greshakes auf eine Naturalisierung des gesamten Auferstehungsgedankens hinaus: „Wenn es das Wesen der Seele ist, ,forma' zu sein, dann ist ihre Zuordnung auf Materie hin unaufhebbar und man müsste sie selber auflösen, um ihr dies zu nehmen; insofern entsteht hier eine anthropologische Logik, die Auferstehung als Postulat des Menschseins erscheinen lässt. ${ }^{{ }^{60}}$ Auf jeden Fall führt die These, dass vollendete Leiblichkeit dasjenige ist, was unter Absehung von irdischer Körperlichkeit unmittelbar im Tod konstituiert wird, für Ratzinger in einen neuen Dualismus hinein, in dem das Scheitern des ganzen Arguments, wie es Greshake vorträgt, offensichtlich wird. Vollendbar, sozusagen eschatologisch hoffähig ist nur die idealistisch umgedeutete, ins Seelische „aufgehobene" Leiblichkeit. Was wir hier und jetzt noch als notwendige Bedingung unserer leiblichen Existenz kennen, bleibt in der transmortalen Endläuterung als abgestoßene „Schlacke“ im Grab und damit aus der Hoffnung des Heils ausgeschlossen. Aus der Perspektive vollendeten Menschseins fällt dieses Stück Welt ins Nichts zurück. Man darf diese Kritik Ratzingers gewiss nicht so verstehen, als postuliere er selbst Auferstehung als "Zurücknahme“ des material identischen irdischen Leibs - auch in seinen späteren Beiträgen zur Debatte ist er nicht in jene „Verklärungsphysik“ der Tradition zurückgefallen, die er ausdrücklich immer wieder kritisiert hat. ${ }^{61}$ Vielmehr geht es ihm in einer prinzipielleren Per-

38 Vgl. Rahner, Immanente und transzendente Vollendung (1967), bes. 608. Dazu: Sonnemans, Seele (1984), 448ff.; Kirk, Tod und Unsterblicbkeit (1986), 204-219.

59 Ratzinger, Eschatologie ('1977), 148.

60 Ebd.

61 Vgl. etwa Ratzingers Bemerkungen zur Auferstehungsleiblichkeit im Beitrag Die Auferstehung Christi und die christliche Jenseitshoffnung (1972), 35, wo zwar eine schroffe Entgegensetzung von „Auferstehung des Fleisches" und „Unsterblichkeit der Seele" bereits klar abgelehnt, bezüglich der Auferstehungsvorstellung aber hinzugefügt wird: „Wieweit mit diesem Wort auch ein sozusagen naturgeschichtliches Ereignis gemeint ist - dass am Ende die einzelnen Körper den Menschen zurückgegeben werden -, ist, wie mir scheint, eine sekundäre Frage, die auch von der Bibel keineswegs eindeutig beantwortet wird. Sicher erwartet die Heilige Schrift und erwartet es der christliche Glaube aller Zeiten, dass die Ge- 
spektive um das „Schicksal der Materie“ als dem irreduziblen Medium menschlichen Leibseins. Der Leib im Grab wird zum Symbol derjenigen Dimension von „Menschsein in der Welt", die der Tod eines Menschen sehr real als noch nicht gänzlich Verinnerlichtes erweist. ${ }^{62}$ Für sie heißt Hoffnung auf Vollendung, dass sie in einem durch die endgültige Gottesbeziehung vollendeten Menschsein „verklärt" wird, ohne damit ein Moment ganz in oder an der Seele werden zu müssen. Auch in der Glorie bleibt sie ein zu Formendes, das Sich-Ausdrücken der Form Aufnehmendes. ${ }^{63}$ Traditionell ausgedrückt: Es geht um die Vollendbarkeit des Menschen als „ens compositum “ und darin um Vollendbarkeit der Materie durch die Seele, aber nicht in ihr. Eschatologie muss die Hoffnung beinhalten, dass die gottgewirkte „Umkehrung der Verhältnisse auch eine ganz neue Verhaltensform der Materie herbeiführen kann"64, deren Beschaffenheit im einzelnen unserem jetzigen Verstehen entzogen bleibt.

schichte am Schluss zu einem Ende kommt, dass die Menschheit damit als ganze sich erfüllen und dass die Welt der Materie darin eine endgültige Bedeutung gewinnen wird. Das sind sozusagen die Elemente, die man als sicher angeben kann. Über Details zu fragen, scheint mir dagegen letzten Endes sinnlos und auch überflüssig zu sein." "Physizistisch" wird man solche Aussagen wohl kaum nennen können. Ratzingers eigentliches Anliegen ist hier die Auferstehung „am Ende der Zeiten“, nicht die Betonung einer irgendwie identischen Leiblichkeit. Ob im Laufe der Jahre Ratzingers Thesen zumindest eine Tendenz hin zu eher traditionell-physizistischen Formulierungen erkennen lassen, würde eine exaktere Untersuchung erfordern. Wenn manche Formulierungen, wie z. B. das vorsichtige Votum zugunsten der These, dass "Gott in biologische oder physikalische Vorgänge eingegriffen haben“ könnte, in diese Richtung deutbar scheinen (Damit Gott alles in allem sei [1993], 122), muss darauf hingewiesen werden, dass sehr frühe Beiträge Ratzingers ebenfalls schon betont haben, dass „die Auferstehung an den ,Reliquien' des alten Erdenleibs nicht vorbeigeht, soweit sie noch eindeutig als solche vorhanden sind", während zugleich die Nutzlosigkeit eingehenderer Spekulationen über die Beschaffenheit dieser zukünftigen Wirklichkeit betont wurde (Art. Auferstebungsleib [LThK], 1053).

62 Dass Ratzingers Ablehnung einer Auferstehung im Tod sich auch in seinem Verständnis des Todes selbst ausdrückt, kann hier nur angedeutet werden. Auch dieser Teil seiner Eschatologie grenzt sich von allzu idealistischen Entwürfen, wie etwa Rahners ganz vom Begriff des aktiven, endgültigen Selbstvollzugs her verstandenen Sterbens, ab. Vgl. dazu: Der Tod und das Ende der Zeiten (1961), 102-107; Zur Theologie des Todes (1973); Eschatologie ('1977), 65-91.

63. Diese Formulierungen gehen über das bei Ratzinger explizit zu Findende hinaus. Kritisch wäre zu fragen, ob Ratzinger die ontologischen Implikate seiner Kritik an Greshakes eschatologischem Materie-Begriff nicht konsequenter hätte ausformulieren müssen. Bleibt auf ihrem Hintergrund z. B. die Vorstellung eines Allkosmisch-Werdens der verherrlichten Seele, wie ihn Ratzinger von Rahner übernimmt, im strengen Sinn denkbar?

64 Ratzinger, Art. Auferstebung des Fleiscbes (LThK), 1050. Im gleichen Artikel spricht Ratzinger allerdings auch davon, dass in dieser Vollendung der Geist 
(bb) Der zweite Hauptvorwurf Ratzingers richtet sich auf das bei Greshake bestimmende Zeit- und Geschichtsverständnis. Nach Greshake tritt der Verstorbene aus der Erdenzeit als ganzer Mensch ein in die vollendete Ewigkeit Gottes. Zeitliche Existenz mündet unmittelbar in vollendet ewige. Dagegen richtet Ratzinger zunächst einige grundsätzliche Fragen: „Stimmt es denn eigentlich, dass es nur die Alternative zwischen physikalischer Zeit und Nicht-Zeit gibt, die dann mit Ewigkeit identifiziert wird? Ist es logisch überhaupt durchführbar, den Menschen, der das Entscheidende seiner Existenz als Zeit vollbracht hat, in die Verfassung purer Ewigkeit zu versetzen? Kann denn begonnene Ewigkeit überhaupt Ewigkeit sein? Ist nicht etwas dadurch, dass es einen Beginn hat, notwendig nicht-ewig, zeitlich? Kann man aber leugnen, dass die Auferstehung des Menschen einen Beginn hat, nämlich nach seinem Tod ?" ${ }^{65}$ Freilich bilden die Rückfragen zur grundsätzlichen Überführbarkeit zeitlicher Existenz in einen überzeitlichen Seinsmodus nicht den Kern seiner Kritik. Diese knüpft vielmehr grundlegend an der Bestimmung des Verhältnisses zwischen der bei Greshake behaupteten Vollendung von Geschichte im individuellen Tod und dem Faktum der fortschreitenden Gesamthistorie der Menschheit an. Ratzinger möchte sich nicht mit der Vorstellung abfinden, dass jeder Verstorbene eingeht in den eschatologisch bereits vollendeten Modus geschichtlicher Existenz, während zugleich die Geschichte weiterläuft. Denn sofern ein solches Modell nicht selbstwidersprüchlich werden will, muss es gleichsam das Ende der Geschichte ins Jenseits der Geschichte verlegen. ${ }^{66}$ Weshalb dies kein gangbarer Weg ist, werden wir im Zusammenhang mit Ratzingers eigener Lösung noch erfahren. Die formale Parallele zum ersten Kritikpunkt ist aber bereits jetzt offensichtlich: Die These von der „Auferstehung im Tod" muss wie für die "Materialität" so auch für die "Geschichtlichkeit" des Menschen einen Vollendungsmodus postulieren, in dem Aspekte des Menschseins, wie sie sich in unserem empirisch abgesicherten Weltwissen als konstitutiv erweisen, reduktionistisch ausgeblendet werden. Es ist dagegen in Ratzingers Sicht die Stärke der alten Zwischenzustandslehre, dass sie das Vorläufige, Unbefriedigende des Schon-Vollendetseins der Einzelexistenz angesichts des Noch-nicht-Vollendetseins des Gesamtkosmos zum Ausdruck zu bringen vermag.

(cc) Ratzingers Gesamturteil über die These einer „Auferstehung im Tod" fällt nach dieser Einzelkritik sehr scharf aus. Er spricht von

\footnotetext{
„Ort“ dieser verklärten Materie sein wird, wie jetzt noch umgekehrt die Materie „Ort ${ }^{\alpha}$ des Geistes ist.

65 Eschatologie ('1977), 96.

66 Vgl. Das Ende der Zeit (1999), 18.
} 
„einem so vertrackten hermeneutischen Flickwerk, das voller logischer Risse und Sprünge ist", und schließt die unmissverständliche Forderung an: „Man sollte danach trachten, möglichst schnell ein Denken zu verabschieden, das die Verkündigung sprachlos macht und sich damit als Weise des Verstehens selbst aufhebt. ${ }^{167}$ In einem 1980 publizierten Artikel anlässlich der seine eigene Position stützenden „Erklärung der Glaubenskongregation zu einigen Fragen der Eschatologie ${ }^{\omega_{68}}$ (vom 17.5.1979) verschärft er den Ton noch, indem er die These einer „Auferstehung im Tode“ nicht bloß als Ursache theologischen Sprachverlustes in der Verkündigung und als ersten Schritt zu einer generellen Leugnung des Auferstehungsglaubens identifiziert ${ }^{69}$, sondern, wie im ersten Teil unseres Textes angedeutet, geradezu zum Musterbeispiel für die aktuelle, der reformatorischen nicht unähnliche Krise des Katholischen erklärt, nämlich den „Bruch der Traditionskontinuität als Grundproblem hinter der Revolutionierung der einzelnen theologischen Themen"

(c) Dagegen stellt Ratzinger eine eigene Sicht von „Auferstehung (am Jüngsten Tag) “ , die mit der traditionellen Rede von einer unsterblichen Seele und einem zwischen Tod und Auferstehung obwaltenden Zwischenzustand vereinbar bleibt. Was mit "Seele" einerseits und „Auferstehung " andererseits gemeint ist, so unterstreicht unser Theologe, sind „nicht Gegensätze, sondern komplementäre Aussagen für die Stufungen einer einzigen Hoffnungsgewißheit ${ }^{\alpha 71}$. Der theologische Erklärungsversuch, den Ratzinger dafür vorlegt, ist nun wiederum alles andere als traditionalistisch, sondern greift im Gegenteil unbezweifelbar moderne Momente der anthropologischen Vermittlung dieser Glaubensaussagen auf.

67 Eschatologie ('1977), 98.

68 Vgl. Zwischen Tod und Auferstehung (1980), 212: „Das Kirchliche Lehramt hat mit diesem Schreiben in einen theologischen Disput eingegriffen, in dem es die Grenze der Theologie berührt sah: Die Auflösung des Seelenbegriffs...“. Die Aussagen des Artikels finden sich auch als "Anhang 2" in Ratzingers Eschatologie ('1980), 211-226. Greshake nannte das römische Dokument unverhohlen "verunglückt", da es in der letztlich offiziellen Fassung an einer Stelle gegenüber der ursprünglich verschickten Briefform ergänzt werden musste; vgl. Greshake, $A u f-$ erstebung im Tode (1998), 542; ausführlicher: Greshake, Zum römischen Lebrschreiben (1982).

Vgl. Ratzinger, Zwischen Tod und Auferstebung (1980), 218.

70 Ebd. 220, vgl. zuvor 214. Fairerweise muss aber betont werden, dass Ratzinger selbst auf diesem Höhepunkt der Auseinandersetzung eine „Verketzerung ${ }^{\text {“ seiner }}$ Kontrahenten explizit abgelehnt hat: „Damit soll in keiner Weise die theologische Arbeit von Greshake und Lohfink in die Nähe der Häresie gerückt werden. Auch wenn ich der Logik ihres Denkens nicht folgen kann, habe ich den Ernst und das Vorwärtstreibende ihrer Gedanken nie bestritten ${ }^{*}$ (ebd. 219).

71 Ebd. 213. 
(aa) Ratzingers Grundansatz ist die - von der augustinischen Zeitanalyse in Conf. XI inspirierte - Differenzierung verschiedener Gestalten von "Zeitlichkeit" " Dieser Ansatz ist insofern bemerkenswert, als zeittheoretische Überlegungen, näherhin der Verweis auf die Inkompatibilität von irdischer Zeit und „Ewigkeit“, nach Ratzingers eigener Aussage bei den Theologen der gegnerischen Fraktion zu den entscheidenden Argumenten für die Vorstellung eines Zusammenfalls von persönlichem Tod und Auferstehung zählen. ${ }^{73}$ Somit wird die Bewältigung des Zeitproblems auch für denjenigen zum entscheidenden Schlüssel, der diese These vermeiden will.

Ratzinger erkennt von seinem augustinischen Fundament her problemlos die Zentralidee der neueren Unterscheidungen zwischen Zeit und Ewigkeit an, in welchen die Vorstellung einer "unreflektierten Linearität, in der das, was als Ende selbst nicht mehr Zeit ist, einfach ,nach' der Zeit angeordnet und damit selbst zur Zeit gemacht wird "74, vermieden werden soll. Was er aber in vielen Stellungnahmen vermisst, ist die Berücksichtigung des anthropologischen Propriums in kategorialen Distinktionsschemata zum Zeitbegriff. Er selbst macht folgenden Vorschlag: Menschliche Zeit, wie sie als Frucht bewusst geführten Lebens im Tod als Erinnerung ( memoria $^{\text {") }}$ gegenwärtig bleibt, ist nicht identisch mit bloßer physikalischer Zeit, die sich am Umlauf der Gestirne misst. Anthropologische, menschlich erfahrene Zeit hat eigene Erlebnisqualität und auch eigene Konstitutionsgehalte. In dieser durch das Sterben verendgültigten Zeit eines Menschen nun wird notwendig die Bindung an andere Menschen und damit an deren Zeit bewahrt; das konstitutiv dialogisch-kommuniale Moment menschlichen Lebens prägt dessen "Zeit" über ihr Ende hinaus. Die bloße Alternative von (physikalischer) Zeit und (ganz zeitloser, ihr inkommensurabler) Ewigkeit ist damit aufgebrochen. "Das bedeutet dann, dass sich beim Heraustreten des Menschen aus der Welt des Bios die Memoria-Zeit von der physikalischen Zeit löst und dann als reine Memoria-Zeit bleibt, aber nicht zu ,Ewigkeit" wird." "7s Anders ausgedrückt: Das Sterben ist ein Heraustreten des Einzelnen aus der Geschichte, aber doch nicht einfachhin Eintreten in das "reine Heute ${ }^{\alpha 76}$, in die eschatologische Vollendung. Denn der Verstorbene "verliert nicht die Beziehung auf die Geschichte, weil das Netz der menschlichen Relationalität zu seinem

7 Noch auf dem gemeinsamen Symposium mit Johann Baptist Metz 1999 hat Ratzinger auf diesen Ansatz zurückgegriffen: Das Ende der Zeit (1999), 13f. Vgl. auch die umfassende Darstellung bei Nachtwei, Dialogische Unsterblichkeit (1986), 74-115. Vgl. dazu Jenseits des Todes (1972), $234 \mathrm{f}$.

Ebd. 236.

75 Eschatologie ('1977), 152. Vgl. zuvor schon: Jenseits des Todes (1972), $236 \mathrm{f}$. 
Wesen selber gehört." 77 Gerade dieses bleibende Verbundensein des Toten mit der noch offenen Menschheitsgeschichte, die das NichtVollendetsein der Seele vor dem Jüngsten Tag notwendig macht ${ }^{78}$, sieht Ratzinger in der Auferstehungslehre Greshakes missachtet - ja missachtet wird dort letztlich Gottes Verbundenheit mit derjenigen Geschichte, in die er selbst als Mensch eingetreten und für deren Rettung er in den Tod gegangen ist. Für den "Gott, den wir am Kreuz Christi kennenlernen“, so drückt es Ratzinger aus, „ist die Geschichte so real, dass sie ihn in die Scheol führt und dass der Himmel erst wahrhaft und endgültig Himmel sein kann, wenn er über einer neuen Erde steht." ${ }^{\text {"79 }}$ Wie Gott selbst in Christus zwar antizipativ die Entscheidung der Geschichte herbeigeführt hat (man erinnert sich an den Grundgedanken Cullmanns!), aber zugleich auf die reale Rettung auch des „letzten Leidenden “ wartet, muss auch die schon erfüllte Liebe der Geretteten (traditionell ausgedrückt: die in der Anschauung Gottes beseligte „anima separata") zugleich offen bleiben für "die noch immer reale, real weitergehende und real leidende Geschichte ${ }^{\text {«80 }}$, die erst dann vollendet ist, wo der einzelne seinen Platz „im Ganzen“ erhält ${ }^{81}$ - und das ist am Tag der Auferstehung und des Allgemeinen Gerichts. Auferstehungshoffnung trägt in sich „das Nein zur Vereinzelung des Menschen, die Zuordnung des Ich auf das Wir hin "82. Erst im Geschehen des Jüngsten Tages wird diese kommuniale, mitmenschliche Dimension, auf die der einzelne Mensch ebenso ausgerichtet ist wie der in Christus menschgewordene Gott, volle Realität. Letztlich mündet Ratzingers Kritik an der These von der "Auferstehung im Tod" somit in den gewichtigen Vorwurf, dass in ihr das Anliegen der Menschwerdung Gottes selbst nicht mehr in all seinen Dimensionen verstehbar wird. Greshake scheint die Geschichte für die Toten abzuschließen, wo sie in der Logik der göttlichen Liebe in Wahrheit noch offen sein muss - hier zeigt sich Ratzinger (ähnlich wie Hans Urs von Balthasar) am Rande der escha-

7 Eschatologie ( $\left.{ }^{1} 1977\right), 152$.

78 Diese (in gewissem Sinn gegen die thomanische Lehre einer intensiven Vollkommenheit der rein seelischen Glückseligkeit nach dem Tod gerichtete) Ansicht betont Ratzinger ausdrücklich in: Zwischen Tod und Auferstehung (1980), 221, Anm. 20.

79 Eschatologie ('1977), 155.

so Ebd.

81 Vgl. ebd. 157. Dieser Gedanke taucht an vielen Stellen in Ratzingers Werk auf; genannt seien nur: Einfübrung (1968), 295: „Und weil es der Mensch selbst ist, der leben wird, nicht eine isolierte Seele, darum gehört das mitmenschliche Element mit in die Zukunft hinein; darum wird die Zukunft des einzelnen Menschen erst dann voll sein, wenn die Zukunft der Menschheit erfüllt ist“; Auferstebung und ewiges Leben (1973), 308f.

12 Heilsgeschichte und Eschatologie (1967), 85. 
tologischen Debatte als Theologe, der anders als im klassischen griechisch-aristotelisch geprägten Gottesbild der Scholastik den Gott Jesu Christi nicht als radikal geschichtslosen, von der Zeit unberührten betrachten will, sondern der vielmehr seine Ewigkeit als „Zeitmächtigkeit ${ }^{\star}$ und damit als ein ihn selbst betreffendes Sich-beziehen-Wollen auf die Welt interpretiert. ${ }^{83}$

(bb) Wenn nun am Jüngsten Tag tatsächlich Vollendung möglich wird, dann - so setzt Ratzinger auch gegen die erste von ihm bei Greshake kritisierte These seinen Kontrapunkt - wird sie die Materie in ihrer Ganzheit umfassen, wie wir sie in der jetzigen Welt kennen. Die Lösung besteht nicht in einer Epiphänomenalisierung oder Ausgrenzung des „bloß" Materiellen, sondern in der Hoffnung auf dessen neue und endgültige In-Beziehung-Setzung zum Geistigen, in dem alle Entfremdung zwischen Geist und Materie, Gott und Welt ihr Ende findet. Das „All-kosmisch-Werden“ der Seele des Menschen im Tod" ${ }^{84}$, so Ratzingers These, wird sich vollenden in "universalem Austausch" zwischen Seele und Leib, in einem Verhältnis des Sich-Durchdringens und -Einbegreifens, der (wie auch Ratzinger durchaus sagen möchte) „Verinnerlichung ${ }^{\text {"85, }}$, in einem sich unserem jetzigen Verstehen im Einzelnen entziehenden Zustand höchster Komplexität, der auch das Streben der Materie an ihr Ziel bringt. ${ }^{86} \mathrm{Hier}$ verbindet Ratzinger das klassische theologische Modell der leiblichen Verklärung, die möglich wird durch das „Überfließen“ des seelischen Glorienlichts auf den in der Aufer-

83 Vgl. Art. Ewigkeit (LThK), 1269. Dasselbe wird noch einmal sehr deutlich in Das Ende der Zeit (1999), $18 \mathrm{f}$.

84 Diese Vorstellungskategorie Rahners klingt bei Ratzinger auch in neueren eschatologischen Äußerungen immer wieder an; vgl. Gott und die Welt (2000), 375f.: "So wie wir Gott nicht in einer bestimmten Wolkenhöhe ansiedeln können, so ist auch der Tote in einem anderen Verhältnis zur Materialität. Das Verhältnis Gottes zum materiellen Raum ist eben ein Verhältnis des Durchherrschens. Wir sprachen schon von Stufen der Nähe Gottes, die nicht durch räumliche Orte bedingt sind, und wir sagten ebenfalls, dass auch die Seele, das geistige Prinzip im Menschen, nicht wie ein bestimmtes Organ an irgendeinem Punkt sitzt, sondern wiederum eine Form des Bestimmens des Ganzen darstellt. So ähnlich ist auch der Tote an der anderen Raumbeziehung Gottes beteiligt, die ich nicht nach geographischen Kategorien festlegen kann. " $E r$ ist bei Gott - womit er in einer neuen Weise in der Wirklichkeit des Alls und so auch mir nahe ist." Vgl. Eschatologie ( $\left.{ }^{6} 1980\right), 222$.

86 Vgl. Einfübrung (1968), 266ff. und 299: „Wenn der Kosmos Geschichte ist und wenn die Materie ein Moment an der Geschichte des Geistes darstellt, dann gibt es nicht ein ewiges neutrales Nebeneinander von Materie und Geist, sondern eine letzte "Komplexität", in der die Welt ihr Omega und ihre Einheit findet. Dann gibt es einen letzten Zusammenhang zwischen Materie und Geist, in dem sich das Geschick des Menschen und der Welt vollendet, auch wenn wir heute unmöglich die Art dieses Zusammenhanges definieren können ${ }^{*}$; Von dannen er kommen wird (1967/68), 494ff.; Eschatologie ('1977), 157-160. 
stehung neu geschenkten Leib, mit Motiven aus Rahners Theologie des Todes ("All-kosmisch-Werden der Seele“) und aus Teilhard de Chardins Vorstellung einer sich in der eschatologischen Auferstehung vollendenden Evolution des Kosmos. ${ }^{87}$

(4) Greshake hat auf Ratzingers Kritik gegen die Kernthesen seiner Eschatologie gereizt, ja entrüstet geantwortet. Die dritte Auflage der schon erwähnten Quaestio disputata zum Thema, publiziert 1978, ist in weiten Strecken nichts anderes als eine Zurückweisung der Kritiker, unter denen Ratzinger klar an erster Stelle steht. Eine Rezension der ein Jahr zuvor erschienenen Eschatologie Ratzingers durch Greshake in der Theologischen Revue war vorangegangen. Sieht man von den in solchen Polemiken üblichen Vorwürfen verfälschter Zitierungen, impliziter Selbstwidersprüche des Gegners und des grundlegenden Missverstehens der durch ihn kritisierten eigenen Intentionen $a b^{88}$, findet man in Greshakes Verteidigung seiner These rasch diejenigen beiden Punkte wieder, die wir zuvor als Kern der Ratzingerschen Kritik ausgemacht hatten: das Verständnis von vollendeter Materialität und von vollendeter Geschichtszeit. Sie sind tatsächlich die entscheidenden Kriterien, an denen sich in systematischer Perspektive die im Konflikt liegenden eschatologischen Grundmodelle zu bewähren haben. Greshakes Erwiderung, die in dem 1986 zusammen mit dem Wiener Exegeten Jacob Kremer veröffentlichten Band Resurrectio mortuorum und anderen kleineren Beiträgen weitere Vertiefung fand, nachdem Ratzinger seinerseits 1980 in dem schon erwähnten Artikel und einer um zwei Nachträge erweiterten Neuauflage seiner Eschatologie die Polemik fortgesetzt hatte, lässt sich etwa wie folgt zusammenfassen.

(a) Erstens: Ratzingers Versuch, die Leib-Seele-Dualität in den eschatologischen Aussagen als These zu erweisen, die originär aus der biblischen Botschaft erwachsen und entstanden ist, muss ebenso wie die Bemühung, die Aporien der „anima-separata“-Lehre, wie sie noch bei Thomas von Aquin deutlich zutage treten, interpretatorisch zu entschärfen, als gescheitert angesehen werden. Greshake bleibt dabei, dass es sich dabei um eine sekundär und von außen induzierte Umakzentuierung der biblischen Ursprungsbotschaft handelt: „Die ursprünglich mit dem Auferstehungsglauben gegebene Spannung zwi-

87 Allerdings ist Ratzingers Stellung gegenüber Teilhards allzu optimistischem Fortschrittsdenken mit den Jahren etwas kritischer geworden; man vgl. etwa Einführung (1968), 192ff. und Eschatologie und Utopie (1977), 109. Siehe auch Modemann, Omegapunkt (2004).

gg Vgl. Greshake, Leib-Seele-Problematik (1978); die polemische "pars destruens" füllt hier bes. die Seiten 160-164. Übrigens hat sich auf der anderen Seite Ratzinger ebenso über "die extreme polemische Vergröberung ${ }^{*}$ seiner Gedanken beklagt: Eschatologie ( 61980$), 196$. 
schen postmortaler Vollendung des Individuums und endzeitlicher Vollendung des Ganzen wurde [...] umgeformt zur Spannung zwischen Vollendung der Seele und Vollendung des Leibes im Blick auf den je einzelnen Menschen "89 Die ausführliche biblische und historische Argumentation zur Abstützung dieser Behauptung, wie Greshake sie verschiedentlich entfaltet hat, muss hier ausgeklammert bleiben. Gleiches gilt für den Gegenstandpunkt Ratzingers, der bis in die jüngste Gegenwart auf die klare Rezeption jüdischer Zwischenzustandsvorstellungen in der Verkündigung Jesu verwiesen hat. ${ }^{90}$

(b) Zweitens: Mit der These einer "Auferstehung im Tod" braucht nach Greshake der Begriff der unsterblichen Seele nicht vollends aufgegeben zu werden, da sie als dasjenige Moment im Auferstehungsgeschehen benannt werden kann, das personale Kontinuität über den Tod hinaus sichert. ${ }^{91}$ Ebensowenig muss die Vorstellung einer „Auferstehung am Jüngsten Tag“ als Garant des notwendigen Bezugs, den der einzelne Mensch zur Menschheit als ganzer und zur vollendeten $\mathrm{Ge}$ schichtszeit besitzt, einfachhin wegfallen. Greshake will durchaus "Auferstehung der Toten" als dynamisches Prozessgeschehen der Vollendung des „Leibes Christi“ denken, das durch die Auferstehung Jesu begonnen und ermöglicht ist und das mit dem Eingefügtwerden eines jeden Gliedes voranschreitet, bis auch der letzte Bruder und die letzte Schwester ihr ewiges Ziel erreicht haben. ${ }^{92}$ Damit sieht Greshake die von Ratzinger so vehement eingeforderte offene Relationalität der Verstorbenen zur noch nicht vollendeten Weltgeschichte hinreichend gewahrt: „Als vollendeter Mensch lebt der Heilige bei Gott und wartet auf die Vollendung der Communio Sanctorum. Wer im Tod erstanden ist, wartet auf die Auferstehung aller" ${ }^{93}$ In der verstärkten Betonung dieser Prozessualität des Vollendungsgeschehens in späteren Beiträgen Greshakes kann durchaus ein gewisses Eingehen auf Ratzingers Kritik erkannt werden. Auch seine Sicht von einer positiven Beziehung Gottes auf die noch nicht vollendete Geschichte ist kaum von derjenigen Ratzingers verschieden. ${ }^{94}$ Der Freiburger Dogmatiker geht so weit, die von

89 Greshake, Theologiegeschichtliche und systematische Untersuchungen (1986), 257. Vgl. auch Greshake, Rezension 481.

Vgl. die nur auf dem Hintergrund dieser Debatte verständlichen Randbemerkungen im Kapitel zum Lazarus-Gleichnis in Ratzingers Jesus Buch, die im Fazit münden: „Eine ,Auferstehung im Tod' kennt Jesus nicht": Ratzinger, Jesus von Nazareth (2007), 256.

9 Vgl. Greshake, Theologiegeschichtliche und systematische Untersuchungen (1986), $269 f ., 274$.

92 Vgl. ebd. 266; Greshake, Auferstebung im Tod (1998), 543.

93 Ebd. 557.

94 Vgl. etwa ebd. 546f. (gegen Thesen bei Ulrich Lüke): „Indem Gott eine zeitverfaßte Schöpfung ins Werk setzt, ,verzeitlicht' er sich in Freiheit selbst. Seine 
Ratzinger verteidigte traditionelle Sichtweise, wenn man sie nur recht versteht, und seine eigene Interpretation als „komplementäre Modelle“ nebeneinanderzustellen, die jeweils gültige Teilaspekte der einen eschatologischen Wirklichkeit benennen ${ }^{95}$ und mit der theologischen Sprachregelung im Raum der Kirche zu verbinden $\operatorname{sind}^{96}$. Auch Ratzinger hat in jüngeren Veröffentlichungen bei allem bleibenden Gegensatz der Positionen hier einen Punkt der Vermittlung zum Denken Greshakes anerkannt. $^{97}$

(c) Drittens: Scharf bleibt Greshakes Abgrenzung gegenüber Ratzinger dagegen in der zweiten Kontroversfrage, dem Verständnis von Materialität in der menschlichen Vollendung. „Mit diesem Differenzpunkt“, so Greshakes Urteil, „ist eine wirkliche Sachdifferenz gegeben. " ${ }^{\text {" D8 }}$ Den Kontrahenten trifft hier der Vorwurf, Auferstehung letztlich nur „physizistisch“ denken zu können, „nämlich im Grunde doch als Hinwegnahme des Leibes, so dass angesichts des Leichnams (...) nicht von Auferstehung gesprochen werden kann. "99 Greshake bleibt dagegen bei seiner an Rahner und einer stark idealistischen Thomasdeutung (z. B. bei Johann Baptist Lotz) orientierten These, dass Materie im Tod ganz verinnerlicht, ja „ein begrenztes Moment am Vollzug des Geistes selbst" (Rahner) werde ${ }^{100}$. So erweist sich das Thema der Vollendungsfähigkeit von Welt und Materie und die dahinter stehende Problematik, ob es wenigstens in der Gloriengestalt so etwas wie einen idealistisch-monistischen Schlüssel zur umfassenden Wirklichkeitsbeschreibung gibt, als bis heute offen gebliebenes Problem der langen Debatten um eine „Auferstehung im Tod“, wenn diese selbst mittlerweile auch von ihren Kontrahenten Rat-

Ewigkeit ist seither nicht Zeitlosigkeit und Zeitenthobenheit, sondern Herrschaft über die Zeit und Treue in der Zeit. Solange also die zeitverfaßte Welt währt, steht auch Gott noch in der Zeit."

$95 \mathrm{Vgl}$. Greshake, Theologiegeschichtliche und systematische Untersuchungen (1986), 275, wo die Schlußfolgerung formuliert wird, „dass es letztlich kein Gegensatz ist, zu sagen: Im Tod kommt die Seele des Menschen zu Gott (wobei Seele integral als der eine und ganze leiblich verfaßte Mensch verstanden wird) und: Im Tod wird der ganze Mensch auferweckt (wobei zu assoziieren ist, dass diese Auferweckung erst zu ihrer letzten Vollendung gelangt, wenn die ganze sarx zu Gott heimgekehrt ist). “

96 Vgl. auch Greshake, Rezension 483.

97 Vgl. etwa Ratzinger, Das Ende der Zeit (1999), 17, Anm. 4. Schon in Eschatologie (61980), 198 erwähnt Ratzinger anerkennend, dass sich Greshake zunehmend positiver zum Begriff der Seele geäußert hat.

98 Greshake, Rezension 482.

99 Vgl. Greshake, Theologiegeschichtliche und systematische Untersuchungen (1986), 267f., Anm. 298.

100

Vgl. ebd. 267. 
zinger und Greshake wie in der allgemeinen theologischen Wahrnehmung für beendet erklärt worden ist. ${ }^{101}$

Gewisse Ansatzpunkte für einen Brückenschlag zeigen sich bei exaktem Vergleich der Modelle jedoch auch in diesem Punkt. Es steht fest, dass Ratzinger, wie erwähnt, mit der Tradition die eschatologische Verklärung als ein ganz "von der Seele zum Leib“ verlaufendes Verinnerlichungsgeschehen versteht. Auch sein Modell will den anthropologischen Dualismus überwinden, wenngleich es sich zu einer gewissen bleibenden Dualität bekennt. Ebenso hat Ratzinger immer wieder betont, dass er - anders als scholastische Autoren - die Seele im "Zwischenzustand“ keineswegs völlig „leiblos “ verstehen will. ${ }^{102}$ Wie er sich ihren Leibbezug denkt, hat er nicht allzu ausführlich dargelegt, doch kann kein Zweifel daran bestehen, dass die Vermittlung auch hier wesentlich christologisch erfolgen soll: Die Seele behält im Leib des erhöhten Herrn, der Ort der Verbindung aller Erlösten mit Gott und als mystischer Leib Inbegriff der "Communio Sanctorum" ist, ihren eigenen Gott- und Weltbezug, auch bevor die Geschichte der Welt beendet und sie selbst in der Auferstehung der Toten in ihrem Leib vollendet ist. ${ }^{103}$

4) Das theologische Zentrum: Eschatologie als konkrete Christologie

Nur wenige, ausgewählte Zentralaspekte der Eschatologie Joseph Ratzingers haben wir im Rahmen dieses Beitrags zur Sprache bringen

101 Vgl. die resümierenden, unterschiedliche Bewertungstendenzen verfolgenden Darstellungen bei Kehl, Eschatologie (1986), 275-281; Ziegenaus, Die Zukunft der Schöpfung (1996), 118-129; Alviar, Escatología (2004), 323-332; Wohlmuth, Mysterium der Verwandlung (2005), 168-187.

102 Vgl. Art. Auferstebung des Fleisches (LThK), 1051: „Sie, die im irdischen Dasein wesentl. leibgebunden ist, behält auch im Zwischenzustand zwischen Tod $u$. Auferstehung ihren Welt- u. Leibbezug. “

103 Vgl. Einfübrung (1968), 293: „Wo die, Gemeinschaft der Heiligen“ geglaube wird, ist die Idee der Anima separata (der „losgetrennten Seele“, von der die Schultheologie spricht) im letzten überholt"; Damit Gott alles in allem sei (1993), 138f.: „So wie es in der christlichen Überlieferung gebraucht wird, ist es [sc. das Wort "Seele"] eine Frucht des Glaubens, die in dieser Form außerhalb der Botschaft von Jesus Christus nicht möglich ist und nirgends vorkommt. Es drückt die vom Schöpfer gewollte Besonderheit des menschlichen Wesens aus: Der Mensch ist jenes Geschöpf, in dem Geist und Materie sich begegnen und zu einem einzigen Ganzen vereinen. Wenn wir das Wort Seele beiseite schieben, fallen wir unweigerlich in den Materialismus hinunter, durch den der Leib nicht erhöht, sondern seiner Würde beraubt wird. [...] Denn nach der Himmelfahrt Christi gibt es das Problem der Leiblosigkeit der Seele nicht mehr: Der Leib Christi ist der neue, nun nicht mehr verschlossene Himmel.* 
können. Aber sie dürften ausreichen, um rückblickend die Frage stellen zu können, ob sich ein theologisches Zentrum, eine innere Mitte erkennen lässt, die Ratzingers eschatologische Aussagen im letzten verbindet und trägt. Ohne Zögern kann formuliert werden: Diese Mitte ist für Ratzinger die Verankerung aller eschatologischen Postulate in der Christologie. Was er einmal konkret mit Bezug auf die Naherwartungsfrage formuliert hat, gilt bei ihm ganz generell: „Die eigentliche Konstante ist die Christologie; von ihrer Integrität hängt die Integrität des Übrigen ab, nicht umgekehrt. “ ${ }^{104}$ Christus als „Fleischwerdung des göttlichen Dialogs mit den Menschen“ ist "Auferstehung und Leben“ in Person für alle, die an ihn glauben. ${ }^{105}$ Im Blick auf den "Christus totus" aus Haupt und Gliedern wird der gesamtmenschliche Charakter des Auferstehungsgeschehens verstehbar. Christliche Auferstehungshoffnung ist Frucht der in Christus konkret gewordenen Gottesbeziehung des Menschen - an diesem dialogisch-relationalen Grundansatz des Denkens hat sich bei allem über die Jahre deutlicher akzentuierten Bemühen Ratzingers, die Terminologie der traditionellen Eschatologie gegen allzu scharfe Kritik zu verteidigen, im Kern nichts geändert. ${ }^{106}$ „Die systematische Mitte von Ratzingers Theologie“, so urteilt mit Recht Hansjürgen Verweyen, „bleibt in der gesamten Entwicklung seines Denkens der Begriff vom ,Leib Christi' “ ${ }^{107}$, und dies bestätigt sich nicht zuletzt in der Eschatologie.

Wenn wir auf die von uns angesprochenen Einzelthemen der eschatologischen Debatte zurückblicken, können wir diese christologische Fokussierung überall unschwer wiederfinden. Es ist, wie wir gesehen haben, die in der Geschichte Jesu Christi realisierte und zugleich auf noch zu erwartende Vollendung hinausweisende Nähe der Gottesherrschaft, die der Eschatologie ihren Ort zwischen weltlosem Ruf in existenziale Eigentlichkeit und weltverbesserischem politischem Imperativ zuweist. Es ist der Blick auf das Kreuz Jesu Christi als des Realsymbols einer Liebe, die in der Selbsthingabe an die göttliche Wahrheit den Todesschrecken besiegt, der das originär biblische Verständnis menschlicher Unsterblichkeit freilegt, in dem ontologischer Seelenbegriff und theologisches Relationsdenken vereinbar werden. Es ist schließlich Gottes in

104 Ratzinger, Eschatologie ('1977), 25; vertiefend: Nachtwei, Dialogische Unsterblichkeit (1986), 260-270.

10s Vgl. Ratzinger, Auferweckung (SM), $400 f$.

106 Dies ist in der sorgfältigen Analyse bei Nachtwei, Dialogische Unsterblichkeit (1986), bes. 7-69, klar erwiesen. Vgl. etwa aus der „heißen Phase“ der Debatte mit Greshake die Bemerkungen in: Zwischen Tod und Auferstehung (1980), 222. Was dem Menschen Dauer und Leben gibt, so unterstreicht Ratzinger hier, sind Wahrheit und Liebe. „Der Mensch kann deswegen ewig leben, weil er der Beziehung zu dem fähig ist, was Ewigkeit gibt." Konkret wird dies in der Beziehung zu Jesus Christus. 
der Menschwerdung Christi vollzogenes Eingehen in die Geschichte, die uns nach Ratzinger mahnt, diese Geschichte in unseren eschatologischen Entwürfen nicht durch Aufhebung in eine spiritualistisch-endzeitliche Parallelwelt bereits für beendet und in sich irrelevant zu erklären, während sie doch in Wahrheit noch offen bleibt wie die Freiheitsgeschichte der in ihr lebenden, leidenden, auf Erlösung hoffenden Menschen.

Es wäre leicht nachzuweisen, wie diese christologische Zentrierung sich in vielen weiteren Kapiteln der Eschatologie Joseph Ratzingers fortsetzt, etwa in seinen ganz personalistisch, in spürbarer Anlehnung an Ideen Hans Urs von Balthasars entfalteten Erklärungen der Begriffe Gericht, Fegfeuer, Hölle und Himmel ${ }^{108}$, wenn auch unter Ausklammerung gewisser spekulativer Konsequenzen ${ }^{109}$, und wie sie von hier aus in vielen anderen Feldern seines theologischen Denkens wirksam wird. ${ }^{110}$ Und es wäre ebenfalls nicht schwer aufzuzeigen, wie die wissenschaftliche Reflexion des Theologen Joseph Ratzinger prägend und hörbar bleibt in der apostolischen Lehre des Papstes Benedikt XVI. Einige Sätze aus seiner Predigt zur Ostervigil 2006, die in eingängigen Worten der Verkündigung die christologische Mitte der Eschatologie zum Ausdruck bringen, sollen darum diesen Beitrag beschließen.

"Ich lebe und ibr werdet leben, sagt Jesus im Johannes-Evangelium $(14,19)$ zu seinen Jüngern, das heißt zu uns. Wir leben durch das Mitsein mit ihm, durch das Angeheftetsein an ihn, der das Leben selber ist. Ewiges Leben, selige Unsterblichkeit haben wir nicht aus uns selbst und nicht in uns selbst, sondern durch eine Relation - durch das Mitsein mit dem, der die Wahrheit und die Liebe und darum ewig, Gott selber ist. Die bloße Unzerstörbarkeit der Seele allein könnte ewigem Leben keinen Sinn geben, es nicht zu wirklichem Leben machen. Leben kommt uns aus dem Geliebtsein von dem, der das Leben ist; aus dem Mitlieben und Mitleben mit ihm. Ich, doch nicht mehr ich: Das ist der Weg des Kreuzes, der Durchkreuzung einer bloß ins Ich eingeschlossenen Existenz, und gerade so öffnet sich die wahre, die bleibende Freude. "111

108 Vgl. Ratzinger, Art. Himmel; Hölle (LThK); Eschatologie ('1977), 160-193; Damit Gott alles in allem sei (1993), 137ff.

109 Ganz korrekt nimmt Verweyen, Joseph Ratzinger (2007), 76, wahr, dass Balthasars Nähe zur Allererlösungshoffnung von Ratzinger augenscheinlich nicht rezipiert wird.

110 Erinnert sei nur an die zentrale Rolle, die "die in Kreuz und Auferstehung offen gewordene Menschheit Christi“ als neuer Tempel und Ort eines universalen, auf Einbeziehung der ganzen Menschheit gerichteten Anbetungsopfers für Ratzingers Theologie des Kultes und der Liturgie besitzt; vgl. Der Geist der Liturgie (2000), 30-47 (Zitat hier: 41); Ein neues Lied für den Herrn (1995), 109-112.

11. Benedikt XVI., Predigt in der Liturgie der Ostervigil am 15.04.2006 (Auszug). Quelle: http://www.vatican.va/holy_father/benedict_xvi/homilies/2006/documents/hf_ben-xvi_hom_20060415_veglia-pasquale_ge.html 


\section{Literatur}

\section{1) Beiträge Joseph Ratzingers}

(Bei mehrfach abgedruckten oder aufgelegten Texten ist nur die in unserem Beitrag benutzte Version aufgeführt. Vgl. für weitere Angaben die Bibliographie in: Joseph Ratzinger, Weggemeinschaft des Glaubens. Kirche als Communio [Augsburg 2005] 263-324.)

Artikel im „Lexikon für Theologie und Kirche“, 2. Aufl. (Freiburg 1957-1964): Auferstehung des Fleisches I, VI u. VII: I 1042,1048-1052; Auferstehungsleib: I 1052f.; Ewigkeit II (theologisch): III 1268-1270; Himmel: V 355-358; Himmelfabrt Christi: V 360-362; Hölle: V 446-449; Sterben: IX 1055.

Die Geschichtstheologie des bl. Bonaventura, München 1959.

Der Tod und das Ende der Zeiten, in: Rudolf, K. (Hg.), Die Kirche und die Mächte der Welt. Seelsorge für morgen, Wien 1961, 97-107.

Heilsgeschichte und Eschatologie. Zur Frage nach dem Ansatz des theologischen Denkens, in: Theologie im Wandel. Festschrift zum 150jäbrigen Besteben der kath.-theol. Fakultät an der Universität Tübingen, 1817-1967, München Freiburg 1967, 68-89.

Einfübrung in das Cbristentum. Vorlesungen über das Apostolische Glaubensbekenntnis, München 1968.

Schwierigkeiten mit dem Apostolicum: Höllenfabrt - Himmelfabrt - Auferstebung des Fleisches, in: Brunner, P. (Hg.), Veraltetes Glaubensbekenntnis?, Regensburg 1968, 97-123.

„Von dannen er kommen wird, zu richten die Lebendigen und die Toten ${ }^{\alpha,}$ in: Hochland 60 (1968) 493-498.

Artikel im Lexikon ${ }_{n}$ Sacramentum Mundi“ (1968/69): Auferstehung II: I 397402; Himmelfabrt Christi: II 693-696.

Glaube, Geschichte und Philosophie. Zum Echo auf "Einfübrung in das Christentum ${ }^{\alpha}$, in: Hochland 61 (1969) 533-543.

Glaube und Zukunft, München ${ }^{2} 1971$.

Die Auferstebung Christi und die cbristliche Jenseitshoffnung, in: Adler, G. (Hg.), Christlich - was heißt das?, Düsseldorf 1972, 34-37.

Jenseits des Todes, in: IKaZ 1 (1972) 231-244.

Zur Theologie des Todes, in: Dogma und Verkündigung, München 1973, $277-$ 290.

Was kommt nach dem Tod? in: Dogma und Verkündigung, 291-296.

Auferstehung und ewiges Leben: in: Dogma und Verkündigung, 297-310.

Zukunft des Heils, in: Hommes, U. / Ratzinger, J. (Hgg.), Das Heil des Menschen. Innerweltlich - Christlich, München 1975, 31-63.

Eschatologie - Tod und ewiges Leben = KKD IX (Regensburg $\left.{ }^{1-2} 1977 ;{ }^{6} 1980\right)$.

Eschatologie und Utopie, in: IkaZ 6 (1977) 97-110.

Zwischen Tod und Auferstehung, in: IkaZ 9 (1980) 209-223. 
Politik und Erlösung (= Rheinisch-Westfälische Akademie der Wissenschaften. Vorträge G 279), Opladen 1986.

„Dass Gott in allem sei". Vom christlichen Glauben an das erwige Leben, in:

Kutschki, N. / Hoeren, J. (Hgg.), Kleines Credo für Verunsicherte, Freiburg 1993, 121-140.

Das Ende der Zeit, in: Peters, T. R. / Urban, C. (Hgg.), Das Ende der Zeit? Die Provokation der Rede von Gott, Mainz 1999, 13-31.

Ein neues Lied für den Herrn. Christusglaube und Liturgie in der Gegenwart,

Freiburg 1995.

Aus meinem Leben. Erinnerungen, Stuttgart 1998.

Der Geist der Liturgie. Eine Einfübrung, Freiburg 2000.

Gott und die Welt. Glauben und Leben in unserer Zeit. Ein Gespräch mit Peter Seewald, München 2000.

Jesus von Nazareth. Erster Teil: Von der Taufe im Jordan bis zur Verklärung,

Freiburg 2007.

\section{2) Weitere Literatur}

Alviar, J. J., Escatologia, Pamplona 2004.

Balthasar, H. U. von, Umrisse der Eschatologie, in: Verbum caro. Skizzen zur Theologie I, Einsiedeln 1960, 276-300.

Busch, V., In Gottes Gemeinschaft vollendet. Die Konzeption einer „Auferstehung im Tod" in der Theologie Gisbert Greshakes, Mainz 2001.

Greshake, G., Die Leib-Seele-Problematik und die Vollendung der Welt: Ders. / G. Lohfink, Naberwartung - Auferstebung - Unsterblichkeit (= QD 71), Freiburg ${ }^{3} 1978,156-184$.

Greshake, G., Rezension zu: Ratzinger, J., Eschatologie, in: ThRv 74 (1978) 481483.

Greshake, G., Zum römischen Lehrscbreiben über die Eschatologie (17.5.1979), in: Ders. / G. Lohfink, Naberwartung - Auferstebung - Unsterblichkeit (= QD 71), Freiburg ${ }^{4} 1982,185-207$.

Greshake, G., Theologiegeschichtliche und systematische Untersuchungen zum Verständnis der Auferstehung, in: Greshake, G. / Kremer, J., Resurrectio mortuorum. Zum theologischen Verständnis der leiblichen Auferstehung, Darmstadt 1986, 165-371.

Greshake, G., Auferstehung im Tod. Ein „parteiischer ${ }^{*}$ Rückblick auf eine theologische Diskussion, in: ThPh 73 (1998) 538-557.

Kasper, W., Rezension zu: Ratzinger, J., Einfübrung in das Christentum, in: ThRv 65 (1969) 177-182.

Kirk, P., Tod und Auferstebung innerbalb einer antbropologisch gewendeten Theologie. Hermeneutische Studie zur individuellen Eschatologie bei Karl Rahner, Ladislaus Boros, Gisbert Greshake, Bad Honnef 1986.

Modemann, C., Omegapunkt. Christologische Eschatologie bei Teilhard de Chardin und ibre Rezeption durch F. Capra, J. Ratzinger und F. Tipler, Münster 2004. 
Müller, C., Die Eschatologie des Zweiten Vatikanischen Konzils (= Würzburger Studien zur Fundamentaltheologie 28), Frankfurt a. M. u.a. 2002.

Nachtwei, G., Dialogische Unsterblichkeit. Eine Untersuchung zu Joseph Ratzingers Eschatologie und Theologie (= EThS 54), Leipzig 1986.

Rahner, K., Immanente und transzendente Vollendung der Welt, in: SzT VIII, Einsiedeln 1967, 593-609.

Sonnemans, H., Seele - Unsterblichkeit - Auferstehung. Zur griechischen und christlichen Anthropologie und Eschatologie (= FThSt 128), Freiburg 1984.

Verweyen, H., Joseph Ratzinger - Benedikt XVI. Die Entwicklung seines Denkens, Darmstadt 2007.

Wohlmuth, J., Mysterium der Verwandlung. Eine Eschatologie aus katholischer Perspektive im Gespräch mit jüdischem Denken der Gegenwart, Paderborn u.a. 2005.

Ziegenaus, A., Die Zukunft der Schöpfung in Gott. Eschatologie (= Scheffczyk, L. / Ziegenaus, A., Katholische Dogmatik, Bd. 8), Aachen 1996. 